\title{
EFFICACY OF SINGLE LOADING DOSE OF MAGNESIUM SULFATE IN ECLAMPSIA
}

Meenakshi S. Devarmani, Neeta Harwal

1. Professor. Department of Obstetrics \& Gynecology, M.R. Medical College, Gulbarga, Karnataka.

2. Professor. Department of Obstetrics \& Gynecology, M.R. Medical College, Gulbarga, Karnataka.

\section{CORRESPONDING AUTHOR}

Dr. Meenakshi S. Devarmani,

Professor, Department of Obstetrics \& Gynecology,

M. R. Medical College, Sedam Road,

Gulbarga- 585 105, Karnataka, India.

E-mail: drssdevarmani@gmail.com

Ph: 00919845221901

ABSTRACT: BACKGROUND: Eclampsia is a life threatening condition and it varies from countries to countries. The incidence in our country varies from $5-10 \%$. The first and foremost thing in management of eclampsia is control of convulsions. Magnesium sulphate has established itself as the drug of choice for the anticonvulsant management of eclampsia but the question as to what constitutes the Minimum effective dose remains unanswered which is evident from the different regimens used in clinical practice. Its narrow therapeutic range mandates that it only be used in the minimum doses which gives efficient control of convulsions and helps in improving maternal and fetal outcome. Aims: To study the efficacy and safety of single loading dose of magnesium sulphate in controlling and prevention of recurrence of convulsion in eclampsia, to reduce the adverse affects of magnesium sulphate and improve the maternal and fetal outcome with single loading dose. Methods: Prospective study of 100 cases with clinical diagnosis of eclampsia were given single loading dose of magnesium sulphate [4 $\mathrm{g}$ of $20 \% \mathrm{IV}$ and $10 \mathrm{~g}$ of $50 \% \mathrm{IM}$ ], there was no maintenance dose. The effect of singe loading dose of magnesium sulphate in controlling convulsions, the recurrence rates, toxicity and the maternal and fetal outcome was studied. Results: The results showed a favorable outcome with the reduction of the dose and duration of magnesium sulphate therapy. The primary outcomes were comparable with all other regimens in use. With recurrence rate of $9 \%$ its efficacy was comparable with the other regimens in use. The cases that were on single dose regimen had a significantly lower incidence of cesarean section with up to $74 \%$ of the patients having vaginal deliveries. The maternal mortality was $3 \%$ and perinatal mortality was $29 \%$. Conclusions: Single loading dose of magnesium sulphate is effective in controlling and prevention of recurrence of convulsions in eclampsia. The single most advantage of this regimen was the complete absence of any incidence of magnesium sulphate toxicity and it is easy to administer in any place. Painful injections and monitoring of magnesium sulphate toxicity seen in maintenance dose can be avoided with this regimen.

KEYWORDS: Eclampsia; Magnesium sulphate; Low dose magnesium sulphate.

INTRODUCTION: Eclampsia now a rare disease in developed countries (1:2000 deliveries) where modern antenatal care is available to all pregnant women, as a result preeclampsia is detected early and treated effectively so that the convulsive stage is seldom reached. The 
picture is very different in many developing countries (1:100 to $1: 1700)$ particularly in rural areas where eclampsia may present for treatment in deep coma after many fits at home.

The first and foremost principle of management of eclampsia is control of convulsions. In the recent years with many large studies demonstrating the superiority of magnesium sulfate over other drugs for preventing and controlling eclampsia, magnesium sulfate has become the first line and preferred drug of choice for treatment and prevention of seizures. ${ }^{1}$

Various regimens with different dosages have "been used over the years, question still remains about the 'minimum effective dose' of magnesium sulphate. "If a woman is known to be or appear to be small, the dose should probably be limited".2

Materials and methods: The present study group was 100 patients with eclampsia admitted in the labour room of Basaveshwar teaching and general hospital and Sangameshwar hospital, Gulbarga attached to Mahadevappa Rampure medical college, Gulbarga. The study was started on January 2007. All women with clinical diagnosis of eclampsia were eligible for the study, irrespective of when or where the fits occurred, whether pregnancy was singleton or multiple. A clinical history, thorough physical examination and detailed investigations were carried out for each patient. All the patients were cared for in the eclampsia labour room with intensive monitoring and frequent observations for vital signs. The patients were shifted to postpartum ward only after complete stabilization. Serum magnesium levels were not done due to lack of facilities.

Patients who were throwing convulsions were placed in left lateral position, airway secured; throat suction done, oxygen given if necessary, IV line secured, and urinary catheter inserted mouth gag used to prevent injury to the tongue. Fluid balance was maintained with strict input and output chart. Antibiotic prophylaxis was given to all cases to prevent infection

The single dose magnesium sulphate regimen consisted of: 4 grams of magnesium sulphate as $20 \% \mathrm{MgSO}_{4}$ got by adding 4 ampoules of $50 \% \mathrm{MgSO}_{4}$ in $12 \mathrm{ml}$ of distilled water as IV given slowly over a period of 3-5 minutes promptly followed by 5 grams of $50 \%$ solution ( 5 ampules of $50 \% \mathrm{MgSO}_{4}$ ) injected deep IM in the upper and outer quadrant of one buttock through a 3 inch long, 20 gauge needle.

The effect of singe loading dose of magnesium sulphate in controlling convulsions, the recurrence rates, toxicity and the maternal and fetal outcome was studied.

\section{Antihypertensive Management:}

All the cases were given oral nifedipine, amlodipine and hydrochlorthiazide were used after the BP was stabilized.

\section{Obstetric Management:}

Depending on the favorable state of cervix induction was done using prostaglandin gel, misoprostol vaginal/oral tablets, ARM and oxytocin infusion was used for augmentation of labor. In unfavorable and unresponsive cervix and with other obstetric indications cesarean section was done.

RESULTS: Clinical features: Majority of the patients (55\%) belonged to the age group between 21-29 years. $80 \%$ of the cases belonged to the lower socioeconomic class. $70 \%$ of the cases were not booked. $71 \%$ patients were primi-gravida. 9 Patients gave history of preeclampsia during their past pregnancy and 2 patients had history of eclampsia in the past. Headache was 
the dominant premonitory symptom and it was present in 78 cases followed by vomiting. 5 cases had blindness before the onset of convulsion.

Physical examinations: Most of the patients had MAP between $110-130 \mathrm{~mm} \mathrm{Hg} \mathrm{(60 \% ).}$ Majority had less than 3 episodes of convulsion; only two cases had more than 10 episodes of convulsions. Majority of the patients (84\%) of the patients were brought to the hospital within 6 hrs of onset of convulsion which shows the prompt referrals and improved transport facilities the deficiency of which were responsible for the poor outcome in earlier years. Majority (36\%) were in the gestational age 33 to 36 weeks. Pedal edema was present in $72 \%$ of the patients.

Investigations: Renal parameters were raised in only $10 \%$ of the patients. $46 \%$ had grade- 1 hypertensive changes on fundoscopic examination, $5 \%$ had grade 3 changes one patient had retinal detachment, which improved on post-natal day 5 with conservative management.

Outcome: $76 \%$ of the cases delivered within 12 hours. Those who took longer time were remote from term. Out of 100, 26 patients underwent cesarean delivery whereas 74 delivered through vaginal route. Maternal complications were occurred in 41 patients with most post partum hemorrhage. None of the complications were directly related to magnesium sulphate except thrombophlebitis and injection abscess. 3 out of 100 cases of eclampsia died, one patient died because of intracranial hemorrhage on post natal day 4 (CT showed hemorrhage in the right frontoparietal region with intraventricular bleed). One patient died because of cortical venous thrombosis on postoperative day 6 (patient was in coma for three days). One patient died due to hypovolemic shock, she was G3P2L2 with intrauterine death with abrubtio with severe anemia delivered a still born baby, patient had PPH and developed HELPP syndrome following delivery. Mortality was due to complications of eclampsia and not solely due to magnesium sulphate administration. The first case was switched over to Pritchards regimen as she had recurrence of convulsion after 6 hours. In the remaining two cases, only single dose magnesium sulphate was given. Fetal outcome: At delivery- 73 cases had live birth following delivery. 15 still born cases, 5 abortus and 7 IUD were found. Fetal weight- 55 were in range of 1.6-2.5 kgs, 22 babies were in 1-1.5 kgs. 9 babies were having <1 kg weight. APGAR score in 48 cases was $<5$ at 1 min and 9 cases showed $<5$ at 5 minutes. Unfortunate outcome observed in 29 cases, out of which 13 were still births and neonatal death occurred in 16 cases.

DISCUSSION: The incidence varies from developing to developed countries. The incidence of eclampsia varies from 1 in 100 to 1 in 1700 in developing countries and $l$ in 2000 in developed countries. ${ }^{3}$ The incidence of pregnancy induced hypertension varies from 5-10\%, the incidence of preeclampsia varies from $2-8 \%$ (magpie), and the incidence in India varies from $1-5 \%{ }^{3}$

The developed world has a much lower rate of this complication incidence in UK 4.9/10,000 with a case fatality rate of 1.4\%. (RCOG Guidelines 10;2005). ${ }^{4}$

More than half the cases are antepartum, and approximately $20 \%$ of the cases occurred post partum. Maternal Mortality is 4 to $6 \%$ and the perinatal loss is $45 \%$ and the perinatal loss is $45 \%$ (ICOG Study). ${ }^{4}$

The use of magnesium sulphate in treatment and monitoring of pregnant women with eclampsia and pre eclampsia is well known since centuries. Pritchard JA from U.S.A.in 1955 gets the credit of popularizing magnesium sulphate therapy for eclampsia and his regime is popularly known as "Pritchard's Regime introduced at the Parkland Memorial Hospital. ${ }^{5}$

The Collaborative Eclampsia Trial (CET) published in 1985 found a lowered risk of recurrent convulsions with little difference in maternal, perinatal morbidity and mortality comparing magnesium sulphate with diazepam and phenytoin and concluded that" that there is 
now a compelling evidence in favour of magnesium sulphate rather than diazepam or phenytoin in treatment of eclampsia". Similar findings were also reported by Crowther et ${ }^{6}$ al in their study. Friedman et al, Appleton et $\mathrm{al}^{7}$ and Lucas et $\mathrm{al}^{8}$ in different studies established the superiority of magnesium sulphate over phenytoin validating its long practiced use.

In 1997 Suman Sardesai et al $^{9}$ used the "Low dose magnesium sulphate regimen" in their care centre and published encouraging results with "reduced dose of magnesium sulphate". Our results in terms of clinical features were similar with that study.

In 2002 the results of the 'Magpie trial' another large multicentric trial was published which showed beyond any reasonable doubt the efficacy of magnesium sulphate in reducing the risk of eclampsia.

The present study was started to study the efficacy and safety of single loading dose magnesium sulphate in treatment and prevention of recurrence of convulsions in eclampsia. Results were correlated with other compatible similar studies which are mentioned in table no 1. $71 \%$ of the patients had 3 or lesser number of convulsions, $24 \%$ had 4-6 episodes of convulsions. Convulsions may vary from 1 or 2 in mild cases to even 100 or more in severe and untreated cases or status may ensue (Cunningham et al). ${ }^{10}$

$92 \%$ of the patients had proteinuria. Proteinuria is a feature of glomerular dysfunction and its presence with hypertension doubles the risk of perinatal death (Athula Kaluarachchi 1998).

In the present study 09 cases out of 100 showed a recurrence of convulsions, which is comparable with any of the other standard regimens in use today. One patient had recurrence within one hour and she continued to convulse even after the standard regimen was followed. Details of single dose and recurrence are mentioned in table no 2 .

The results showed a favorable outcome with the reduction of the dose and duration of magnesium sulphate therapy and raises questions about whether the high dose regimens are really necessary and safer. The single most advantage of this regimen was the complete absence of any incidence of magnesium sulphate toxicity. The cases that were on single dose regimen had a significantly lower incidence of cesarean section with upto $74 \%$ of the patients having vaginal deliveries.

The maternal and perinatal outcomes were also comparable with the other regimens. The maternal mortality was 3\%. Perinatal mortality in the present series was $29 \%$ which was comparable with the other regimens considering the fact that almost half of the patients being preterm.

CONCLUSION: Though there appears to be no doubt on magnesium sulphate being the first line drug, the question as to what constitutes the 'Minimum effective dose` remains unanswered which is evident from the different regimens used in clinical practice.

The pioneers of magnesium sulphate therapy like Pritchards and Sibai themselves have opined that each hospital should have their own protocol to suit their patients. The fact that magnesium sulphate is not a safe drug and its narrow therapeutic range mandates that it only be used in the minimum doses which gives efficient control of convulsions and helps in improving maternal and fetal outcome. 


\section{REFERENCES:}

1. MacGillivary I. Effects on the health of the mother in preeclampsia. In I MacGillivary (Ed). The hypertensive disorders of pregnancy 1983; W B Saunders London.

2. Villar M A, Sibai B M. Eclampsia. Am .I Obstet Gynecol 1988; 15: 355-77.

3. Eclampsia trial collaborative group. Which anticonvulsant for women with eclampsia"! Evidence from collaborative eclampsia trial. Lancet 1995; 345: 1455-63.

4. Duley L, Johanson R. Magnesium sulphate for preeclampsia and eclampsia: The evidence so far. B.J Obstet Gynaecol 1994; 101: 565.

5. Pritchard J A. The use of the magnesium ion in the management of eclamptogenic toxemias. Surg Gynaecol Obstet 1955; 186: 601.

6. Crowther $\mathrm{C}$ A. Magnesium sulphate versus diazepam in management of eclampsia: Randomized controlled trial. Br .J Obstet Gynaeco 1990; 97: 110-17.

7. Appleton M P, Kuehl TJ et al: Magnesium sulphate versus phenytoin for seizure prophylaxis in pregnancy Induced Hypertension. Am .J Obstet Gynecol 1991; 165:907.

8. Lucas M J, leveno K J, Cunningham F G. A comparison of magnesium sulphale wilh phenytoin for the prevantion of eclampsia. N Engl J Med 1995; 333: 201.

9. Sardesai Suman, Maira Shivanjali, Patil Ajit, Patil uday. "Low dose magnesium sulphate for eclampsia and imminent eclampsia: regimen tailored for tropical women". J Obstet Gynaecol. 2003; 53: 546-53.

10. Cunningham F G et al. Further observations on nature of pressor responsivity to angiotensin in human pregnancy. Obstet Cynecol 1975; 146;581.

11. Sibai B M. Magnesium sulphate is the ideal anticonvulsant in preeclampsia eclampsia. Am J Obstet Gynecol 1990; 162:1141-45.

12. The Magpie Trial Group. Do women with pre-eclampsia and eclampsia, and their babies, benefit from magnesium sulphate? The Magpie Trial: a randomised, placebo-controlled trial. Lancet 2002; 359: 1877-90.

13. Sardesai Suman, Maira Shivanjali, Patil Ajit, Patil uday. "Low dose magnesium sulphate for eclampsia and imminent eclampsia: regimen tailored for tropical women". J Obstet Gynaecol. 2003; 53: 546-53.

Table no 1:

\begin{tabular}{|l|l|l|l|l|l|}
\hline Study & $\begin{array}{l}\text { Pritchard et al } \\
(1955)\end{array}$ & $\begin{array}{l}\text { Sibai et } \\
\text { al } \\
(1990)^{11}\end{array}$ & $\begin{array}{l}\text { Magpie } \\
(2002)^{12}\end{array}$ & $\begin{array}{l}\text { Sardesai et } \\
\text { al (2003) }\end{array}$ & $\begin{array}{l}\text { Present } \\
\text { study(2007) }\end{array}$ \\
\hline $\begin{array}{l}\text { Recurrence of } \\
\text { convulsions }\end{array}$ & 12.1 & 14.1 & 0.8 & 7.8 & 9 \\
\hline Maternal mortality & 0.4 & 0.4 & 2.6 & 0.2 & 3 \\
\hline Perinatal mortality & 15.7 & 11.8 & 11.4 & 28.5 & 29 \\
\hline
\end{tabular}

*figures in the table are in percentage forms 
Table no 2: details of single dose and recurrences

\begin{tabular}{|c|c|c|c|c|c|c|}
\hline $\begin{array}{l}\text { Total } \\
\text { cases } 9\end{array}$ & $\begin{array}{l}\text { No. } \\
\text { of } \\
\text { convu } \\
\text { lsions }\end{array}$ & $\begin{array}{l}\text { Convulsion } \\
\text { to } \\
\text { admission } \\
\text { interval }\end{array}$ & $\begin{array}{l}\text { MAP on } \\
\text { admission }\end{array}$ & $\begin{array}{l}\text { Type of } \\
\text { eclampsia }\end{array}$ & $\begin{array}{l}\text { Therapy to } \\
\text { delivery interval }\end{array}$ & $\begin{array}{l}\text { Anticonvulsant } \\
\text { used }\end{array}$ \\
\hline \multicolumn{7}{|c|}{$<1$ hour } \\
\hline & 12 & $2 \mathrm{hr}$ & 100 & A & $8 \mathrm{hr}$ & $\begin{array}{l}\text { Single dose+ } \\
\text { Pritchard'sregimen+ } \\
\text { Phenytoin+ } \\
\text { Diazepam }\end{array}$ \\
\hline \multicolumn{7}{|c|}{4 hours (3 cases) } \\
\hline & 4 & 6 & 140 & A & $7 \mathrm{hr}$ & $\begin{array}{l}\text { Single dose+ } \\
\text { Pritchard's regimen }\end{array}$ \\
\hline & 5 & 4 & 126 & A & $8 \mathrm{hr}$ & $\begin{array}{l}\text { Single dose+ } \\
\text { Pritchard's regimen }+ \\
\text { Phenytoin }\end{array}$ \\
\hline & 4 & 4 & 106 & A & $8 \mathrm{hr}$ & $\begin{array}{l}\text { Single dose+ } \\
\text { Pritchard's regimen }\end{array}$ \\
\hline \multicolumn{7}{|c|}{ 5-10 hours ( 4 cases) } \\
\hline & 4 & 8 & 140 & A & $8 \mathrm{hr}$ & $\begin{array}{l}\text { Single dose+ } \\
\text { Pritchard's regimen }\end{array}$ \\
\hline & 4 & 1 & 123 & A & $9 \mathrm{hr}$ & $\begin{array}{l}\text { Single dose+ } \\
\text { Pritchard's regimen }\end{array}$ \\
\hline & 5 & 6 & 116 & A & $8 \mathrm{hr}$ & $\begin{array}{l}\text { Single dose+ } \\
\text { Pritchard's regimen } \\
\text { +Phenytoin }\end{array}$ \\
\hline & 2 & 4 & 120 & I & $4 \mathrm{hr}$ & $\begin{array}{l}\text { Single dose+ } \\
\text { Pritchard's regimen }\end{array}$ \\
\hline \multicolumn{7}{|c|}{ 11-15 hours } \\
\hline & 5 & 2 & 113 & A & $10 \mathrm{hr}$ & \begin{tabular}{|l|} 
Single dose+ \\
Pritchard's regimen
\end{tabular} \\
\hline
\end{tabular}

